\title{
Tin, Aluminum, and Diamonds: Strengthening the Alchemy of the Journal of Social Action in Counseling and Psychology
}

\author{
Lawrence H. Gerstein \\ Ball State University
}

Pamela Valera

Rutgers University, The State University of New Jersey

\begin{abstract}
The purpose of this article is to articulate the incoming Co-Editors' plan, mission, and vision to preserve and enhance the quality and reputation of the Journal of Social Action in Counseling and Psychology. Further, it provides some background about each editor, and offers words of appreciation to the individuals and the academic institutions that support them as Co-Editors.

Keywords: social justice, oppression, inequality, inequity, injustice
\end{abstract}




\section{Introduction}

Assuming the responsibility to serve as Co-Editors of an existing journal with its own established norms, values, expectations, vision, and mission has its benefits in that the journal has an identity and a long-standing history. It also has its challenges like maintaining the journal's quality and reputation, while at the same time potentially modifying its vision and mission. In this article, we articulate our plan to preserve and enhance the quality and reputation of the Journal of Social Action in Counseling and Psychology (JSACP), and we introduce our vision and mission for this periodical. We also will provide some background about ourselves, and share words of appreciation to the individuals and our academic institutions that are supporting us in our role as Co-Editors.

The first issue of JSACP was published in April 2007. Thus, it has been ten years since the launch of this periodical. If we were celebrating a $10^{\text {th }}$ year wedding anniversary, the symbols for this auspicious occasion would be tin, aluminum, and diamonds! Tin is soft and pliable and it is resistant to corrosion. Aluminum is also resistant to corrosion and is pliable, and quite strong

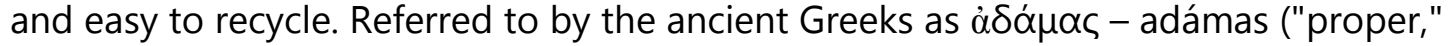
"unalterable," "unbreakable"), diamonds are the toughest naturally occurring materials though as a crystal they are transparent to opaque. In many respects, these symbols for a $10^{\text {th }}$ year anniversary capture the essence, evolution, and potential future for JSACP. Like aluminum and diamonds, JSACP has maintained a strong and unique identity, and like tin and aluminum it has been resistant to corrosion, or stated some other ways, it has stood the test of time or not wavered from its original mission that basically was to promote community change, social action and justice, and system transformation. Further, consistent with the properties of tin and aluminum, the journal also has been pliable demonstrating flexibility in the structure, content, and writing style of articles, and the background of authors giving voice to a diverse group of individuals. Finally, like a diamond, JSACP has been transparent in its mission to shine a light on injustice, inequality, and inequity, and it has confronted and offered solutions to address these different types of oppression to assist marginalized and other effected populations.

The founding editors of JSACP, Tod Sloan and Rebecca Toporek, deserve much credit, respect, and appreciation for navigating its launch, sustaining and strengthening its contents and scope for the past 10 years, and establishing its excellent reputation as an outlet for innovative, relevant, and timely social action and justice research, practice, advocacy, activism, training, and policy development and implementation. It is because of their dedication, hard work, wisdom, and sophisticated leadership along with the assistance of their talented editorial board members that JSACP emerged and continues to be viewed as a high quality and reputable publication outlet. The two organizational sponsors of JSACP, Counselors for Social Justice and Psychologists for Social Responsibility, also deserve our appreciation and admiration for having the foresight and good judgment to invest in launching and continuing to support and promote this journal.

As the new Co-Editors of JSACP, we are quite humbled by the opportunity to follow the extremely talented leadership and vision of Tod and Rebecca. Their stewardship of this journal 
established not only a sound foundation for the solicitation, acquisition, and publication of outstanding social action and justice scholarship, it resulted in facilitating the development of new and creative lines of thought and approaches to address injustice and inequality. Trusting the two of us with your editors' gavel is a great honor, responsibility, and privilege. It also challenges us to strive to achieve publishing articles that rise to the quality, usefulness, and rigor of those you published during your tenure as Co-Editors. We are committed to accomplishing these goals, and like the two of you, we have academic and personal backgrounds that we think we will help us to pursue this important challenge.

\section{Backgrounds of Gerstein and Valera}

Dr. Lawrence H. Gerstein was born and raised by middle class parents in Brooklyn, New York. For his entire life, various family members invested in eliminating the inequalities, injustices, and inequities of society have influenced him. As a teenager in the 1960s, Gerstein was deeply affected by the civil rights and counter culture movement in the U.S. Not surprisingly, beginning in high school, he displayed a strong interest in understanding systems. Gerstein majored in political science with a minor in psychology as an undergraduate. At the crossroads of pursuing graduate school, Gerstein decided to study psychology and not political science. In hindsight, he somewhat regrets this decision.

During graduate school at the University of Georgia where he earned a M.A. (1976) in Rehabilitation Counseling and Ph.D. (1983) in Counseling and Social Psychology, Gerstein organized social justice events to promote Jewish culture in a locale that was generally antisematic and racist. At this same time, he co-led the charge to pass counselor licensure laws in every U.S. state. In the mid-1980s, Gerstein met Taktser Rinpoche, His Holiness The Dalai Lama's oldest brother. Soon thereafter, Rinpoche asked Gerstein to serve as a leader of the Indiana Tibet Committee, an invitation he accepted. In 1995, Rinpoche and Gerstein co-founded the International Tibet Independence Movement. Gerstein served as the President of this not-forprofit organization from 1995-2011. As President, among many different tasks, he organized numerous Marches for Tibet's Independence and walked almost 3,000 miles around North America, managed campaigns to release political prisoners, and assisted Tibetan refugees and immigrants.

Gerstein is a George and Frances Ball Distinguished Professor of Psychology-Counseling at Ball State University where he has been a faculty member in the Department of Counseling Psychology, Social Psychology, and Counseling since 1983 and Director of the university's Center for Peace and Conflict Studies since 2006. In these roles, he has received over $\$ 1.5+$ million dollars in external funding including four U.S. State Department grants and one U.S. Institute of Peace grant designed to teach, in part, conflict prevention and resolution skills to adults, children, and youth in the U.S.A, Jordan, Pakistan, and Tajikistan, and to teach many of these skills to Iraqi young leaders visiting the U.S. Gerstein also has taught the Iraqi young leaders social entrepreneurship skills. Further, Gerstein has performed social justice, prevention, and conflict prevention and resolution work and/or research with adults in China, Hong Kong, Korea, Indonesia, Israel, Taiwan, Tajikistan, and Myanmar. Lastly, he served as co-editor of the 
Handbook for Social Justice in Counseling Psychology: Leadership, Vision, and Action and lead coeditor of the International Handbook of Cross-Cultural Counseling: Cultural Assumptions and Practices Worldwide.

Dr. Pamela Valera is self-identified first generation Assistant Professor in the Department of Social and Behavioral Health Sciences with a secondary appointment in the Department of Urban Health Administration at the Rutgers School of Public Health, The State University of New Jersey. Prior to her faculty appointments at the Rutgers School of Public Health, she was a Research Scientist, with a concurrent appointment as a Research Assistant Professor in the Department of Psychiatry at the New York University School of Medicine.

Dr. Valera is the first in her family to attend college. As a daughter of working-class immigrants, she discovered early on that the voiceless and the marginalized populations have power if we include them in the decision-making process and that inequality and disparities persist among those who have limited institutional resources, social support, and human capital. Dr. Valera received her B.A. in Psychology from the University of San Francisco (1999), her MSW at the University of Michigan (2000), and a Ph.D. in Social Work from the University of South Carolina (2006). After completing her doctorate degree, she was awarded a three-year National Institute of Mental Health T32 postdoctoral research fellowship in human immunodeficiency virus prevention and human sexuality from Columbia University and the New York State Psychiatric Institute (2006-2009), and a one-year research fellowship in cancer health from the Albert Einstein College of Medicine (2009-2010).

She has sustained several years of National Institute of Health/National Cancer Institute funded research in cancer health disparities among men with criminal justice histories at the Albert Einstein College of Medicine, Department of Epidemiology and Population Health and in the Department of Sociomedical Sciences at the Columbia University, Mailman School of Public Health. Her research focuses on developing cancer health education programs for studying cancer prevention and smoking cessation among men involved in the criminal justice system. Through this work, Dr. Valera has made a substantial contribution to the science of cancer health disparities among adults with histories of incarceration. In addition, Dr. Valera is a certified tobacco treatment specialist and the co-chair/co-founder of the Bronx Reentry Working Group (http://bronxreentry.org), a coalition of returning citizens, friends, and family members supporting each other through community reintegration.

\section{The Vision for JSACP}

Our vision for JSACP builds on our backgrounds and extends (content in italics to follow) the mission of JSACP stated upon its inception in 2007. The mission is as follows:

To promote deep reflection on community change and system transformation in which counselors, psychologists, and other human service professionals play a role. This open access journal aims to highlight 'engaged scholarship' and the very important social change work done by professionals and activists that would not normally find its way 
into publication. The journal attempts to break down the divide between theory and practice in one of the most critical areas of our work: social transformation toward social and ecological justice and peace. This journal features action oriented articles, meaning manuscripts that discuss actual work (e.g., advocacy, activism, research, policy formulation and implementation, training, legislation) that has been conducted by the submitting author(s) and not proposed work or simple conceptualizations of issues.

While there are many published articles and book chapters that introduce new or modified social action and/or justice strategies, there is a dearth of research on the actual implementation, evaluation, and empirical investigation of such strategies. Hence, moving forward, JSACP will only publish papers that report on social action and/or justice work that have been performed. We are particularly interested in increasing the number of articles submitted and published that target social action/justice projects involving diverse and/or marginalized populations. Further, we want to publish articles that best fit in one of the four unique sections now featured in the journal:

- Activism and Advocacy

- Education and Training

- Policy and Theory

- Program Development and Evaluation

While many articles to appear in JSACP will be structured and formatted consistent with an empirical paper (i.e., introduction, methods, results, discussion), we also are open to receiving and potentially publishing articles that have an innovative manuscript structure and format, including multimedia. Overall, our intent is to publish timely, innovative, useful, meaningful, and conceptually and methodologically sound social action and/or justice research (program evaluation and implementation) projects relevant to counselors, psychologists, social workers, social scientists, and public health and community educators who function as researchers, practitioners, theoreticians, educators, policy developers and makers, supervisors, and administrators. Additionally, we are particularly interested in the submission of papers that focus on the following topics:

a. Using social action and/or justice strategies in the practice of counseling.

b. Evidence based methodology and strategies to advance the science and practice of social action and justice research.

c. Preventing and effectively responding to oppressive and dangerous political and social movements worldwide.

d. Research, strategies, and programs to effectively address social, political, economic, vocational (e.g., unemployment, descent work), and cultural injustice, inequity, marginalization, and other challenges (e.g., poverty, Islamophobia, antiimmigration, anti LGBTQ+, destruction of Indigenous Peoples' land and sacred spaces). 
e. Research, strategies, and programs on privilege, power, oppression, advocacy, policy, and legislation.

f. Research, strategies, and programs on identity politics and intersectionality.

g. Civic engagement and empowerment with a focus on, for instance, youth or marginalized populations or communities.

h. Hegemonic masculinities and the local, national, and international political leadership.

i. The intersection of climate (environmental) justice and racial (in)justice.

j. Mass incarceration, criminal justice, and mental health.

k. Global social action and/or justice initiatives: Cross-national and cultural practices and research.

I. The pedagogy of social action and/or justice for counseling and psychology.

$\mathrm{m}$. Intergenerational trauma and personal and professional success.

$\mathrm{n}$. Transforming the mental health professions into more social justice and actionoriented professions.

Our commitment to serve as the Co-Editors of this journal would not be possible without the strong support of our academic institutions and departments (Ball State University, Department of Counseling Psychology, Social Psychology, and Counseling; Rutgers University, School of Public Health) for which we are thankful, the journal's publisher, Ball State University's Center for Peace and Conflict Studies, and the current editorial board members who have shared their expertise which has led to strengthening the quality of the papers we will publish. Additionally, our Editorial Assistants (Yamini Bellare, Sam Colbert, and Samantha Hinnenkamp) and first Social Media Editor, Dr. Ashley Hutchison, deserve our appreciation, as they have been quite instrumental in helping us to progress on the goals mentioned earlier. Lastly, we want to thank Tod and Rebecca once again as they both have spent countless hours mentoring us as the new Co-Editors of JSACP. We hope to build on your passion, vision, and remarkable success as editors of JSACP the past ten years. The three articles in this issue accepted by Dr. Toporek and entitled, "Strengthening school-family-community engagement through community dialogues" (Cook, Shah, Brodsky, and Morizio), "A college knowledge outreach program for Latino immigrant parents: Process and evaluation" (Gonzalez), and "Psychotherapy from the Margins: How the pressure to adopt evidence-based-treatments conflicts with social justice-oriented practice" (Rogers-Sirin) are a testimony to the quality of work they published previously in JSACP.

Beyond the topics and types of articles we want to publish in JSACP, we have several other goals we wish to achieve during our tenure as Co-Editors. First, though JSACP has received and published articles submitted by authors worldwide, it has lacked visibility outside of the U.S. We hope that during our tenure of service to the journal, it will become a major outlet and resource for global scholarship on social action and justice. To help achieve this goal, we have already increased the online presence of the journal and increased the frequency of postings on the Facebook (@Journal for Social Action in Counseling and Psychology) and Twitter (@JSACP) accounts for the journal. We created a Social Media Editor position to spearhead these 
endeavors. We request, if you are willing, that you follow the journal on Facebook and Twitter as this will bolster the journal's visibility and most likely expand the number of manuscripts that are submitted.

Next, it is well known that systemic social action and justice strategies are needed to prevent and effectively address complex societal problems and challenges. Often, it is ideal if an interdisciplinary team in collaboration with key stakeholders engages in the conceptualization and assessment of the problem, and the design and implementation of a systemic solution. Assembling such a team enhances the probability that many factors (e.g., cultural, social, economic, political, psychological) and their interaction will be taken into consideration to address the targeted problem or challenge. Historically, JSACP has not received or published many manuscripts written by an interdisciplinary group of authors. Thus, most of the articles that have appeared in JSACP have lacked a multidisciplinary perspective thereby restricting the scope and depth of their impact as well as their ability to address the complex, interwoven contextual and other roots of problems.

We want to overcome this limitation of the journal, and therefore, we highly encourage the submission of manuscripts that report on the implementation and evaluation of a multidisciplinary social action and/or justice solution, particularly papers written by an interdisciplinary team of authors. Third, to enhance the cultural and national representation of the JSACP editorial board, we want to recruit highly published social action and/or justice scholars from around the globe to serve as reviewers. If you meet these criteria, we welcome receiving and reviewing your Vita. Finally, we hope to increase the number of issues of JSACP from two to three per year, the amount of times JSACP articles are cited in other publications, and increase the number of scholarly abstracting and indexing services that carry the journal including, for example, the Social Science Citation Index (SSCI). As a SSCI journal, JSACP will earn an impact factor, a critical milestone these days to demonstrate a journal's credibility and influence. Successfully accomplishing all the goals that we have discussed thus far will help to strengthen $J S A C P^{\prime}$ 's reputation as a primary outlet of literature focused on social action and justice in counseling and psychology.

\section{Conclusion}

We are excited to serve as the second set of Co-Editors of JSACP and anxious to help shape and witness the evolution of this journal. The last ten years have led to a dramatic growth in the interest, relevance, scholarship, and application of social action and justice in the mental health professions. What was once considered on the fringe is now embraced and valued as central to the philosophy, training, and academic pursuits of persons in these professions. In the years to come, we fully expect the creation of new, unique theories of social action and/or justice introduced by individuals affiliated with the mental health professions and reflective of interdisciplinary collaborations. Additionally, we think we will see a much more complex understanding of the intersectionality of identities and the interaction of context and person in such theories. At the same time, in the next decade, we also expect a substantial increase in the development and evaluation of a diverse set of social action and justice strategies resulting in 
the inception of evidence based interventions and best practices in the social action and justice arena. Finally, we believe JSACP will be a major outlet for the publication and dissemination of the various topics we have outlined in this article.

We hope that many of you will join with us as architects and builders implementing the vision we have crystalized in this article as an extension of the editorial stewardship provided by Tod Sloan and Rebecca Toporek the last ten years. Like the metaphor of aluminum, tin, and diamonds we discussed at the beginning of this article, we intend to maintain JSACP's strong and unique identity, one that remains pliable yet transparent in its mission to bring attention to and confront injustice, inequality, and inequity, and articulate solutions to prevent and overcome these dangerous forms of oppression to help marginalized and other effected populations. We look forward with enthusiasm to you submitting your work to JSACP to address the disparities rampant in our society.

\section{Author Contact Information}

Please address correspondence concerning this article to Lawrence H. Gerstein, Ball State University, Department of Counseling Psychology, Social Psychology, and Counseling, Muncie, Indiana 47306 (email: Igerstein@bsu.edu).

\section{Acknowledgment}

We would like to thank Tod Sloan, Rebecca Toporek, Bradley Olson, Rita Chi-Ying Chung, Jane Goodman, Ashley Hutchison, Yamini Bellare, Sam Colbert, Samantha Hinnenkamp, the Counselors for Social Justice, and the Psychologists for Social Responsibility for their support and commitment to this journal. 